\title{
PENDEKATAN ERGONOMI DAN KEARIFAN LOKAL DALAM PERENCANAAN TEKNIS PENATAAN PURA PENATARAN MUNCAKSARI PENEBEL - TABANAN
}

\author{
I.N. Sutarja ${ }^{1}$, I.W. Sukerayasa ${ }^{2}$ I.N. Susanta ${ }^{3}$, I.B.G. Primayatna ${ }^{4}$
}

\begin{abstract}
ABSTRAK
Keberlanjutan pembangunan Pura Penataran di areal Pura Muncaksari yang berlokasi di Desa Sangketan, Kecamatan Penebel - Tabanan memerlukan perencanaan teknis penataan lingkungan pura secara detail yang meliputi tata letak yang jelas, gambar detail dan rencana anggaran biaya yang dibutuhkan. Untuk kegiatan ini masyarakat membutuhkan bantuan tenaga ahli yang sesuai dari Fakultas Teknik Universitas Udayana. Dalam proses perencanaan dan perancangan pura digunakan dua buah pendekatan yaitu 1) pendekatan Ergonomi yang difokuskan pada pendekatan SHIP (Sistemik, Holistik, Interdisipliner, dan Partisipatori dengan menitikberatkan pada Pemberdayaan Masyarakat yang dikaji berdasarkan teknologi tepat guna) dan 2) pendekatan kearifan lokal. Pendekatah SHIP dan teknologi tepat guna diaplikasikan dalam pemilihan sistem struktur dan bahan, sedangkan pendekatan kearifan lokal diaplikasikan dalam pemilihan tata letak dan bentuk. Perencanaan ini menghasilkan gambar denah lingkungan pura Penataran secara keseluruhan dan lingkungan pura Alas Madya yang menunjukkan tata letak pelinggih beserta bangunan pendukung lainnya, gambar detail bangunan dan rencana anggaran biayanya.
\end{abstract}

Kata kunci : ergonomi, kearifan lokal, perencanaan teknis

\begin{abstract}
A detailed temple environmental technical planning, which includes a clear layout, detailed picture and budgeting, is required to support the continued restructuring of the Penataran Temple, which is located at the area of the Muncaksari Temple, Sangketan Village, Penebel District, Tabanan Regency. To this end, the local people need relevant experts from the Faculty of Engineering of Udayana University. Two approaches were applied to planning and designing the temple; they are 1) the ergonomic approach which focuses on the SHIP approach (Systemic, Holistic, Interdisciplinary, and Participatory), which emphasizes the Local People's Empowerment, which was analyzed using the efficient technology, and 2) the local wisdom approach. The SHIP approach and the efficient technology were applied to choosing the layout and determining the shape, producing the map of the whole environment of the Penataran Temple and the map of the Alas Madya Temple which contains the layout of the shrines (pelinggih) and the other supporting buildings, the detailed picture of the buildings and the budgeting .
\end{abstract}

Keywords: ergonomic, local wisdom, technical planning

\section{PENDAHULUAN}

\footnotetext{
${ }^{1}$ Staf Pengajar Program Studi Teknik Sipil, Fakultas Teknik Universitas Udayana., nsutarja_10@yahoo.com.

${ }^{2}$ Staf Pengajar Program Studi Teknik Elektro Fakultas Teknik Universitas Udayana,

${ }^{3}{ }^{4}$ Staf Pengajar Program Studi Arsitektur, Fakultas Teknik, Universitas Udayana
} 
Penataan teknis lingkungan Pura Penataran dalam areal Pura Muncaksari yang berlokasi di Desa Sangketan Kecamatan Penebel Kabupaten Tabanan, belum mempunyai rancangan tata ruang atau tata letak yang terbarukan. Belum mempunyai gambar detail dan rencana anggaran biaya (RAB) yang dibutuhkan untuk penataan teknis lingkungan pura di masa mendatang. Gambar Rencana dan RAB merupakan panduan bagi masyarakat, dalam pelaksanaan penataan, sehingga akan tercapai sasaran penataan teknis lingkungan yang tepat Biaya, tepat Mutu dan tepat Waktu (BMW).

Perencanaan untuk penataan ini memerlukan beberapa tenaga ahli, seperti arsitek, konstruktur dan tenaga ahli lainnya. Tenaga ahli ini tidak dimiliki oleh masyarakat Desa Sangketan, sehingga memerlukan bantuan tenaga teknis ke Program Pascasarjana Teknik Sipil Fakultas Teknik Universitas Udayana.

Berdasarkan keadaan seperti tersebut di atas Program Pascasarjana Teknik Sipil Fakultas Teknik Universitas Udayana merasa berkewajiban untuk membantu dalam hal layanan teknis seperti pengukuran dan pemetaan topografi serta perencanaan penataan teknis lingkungan pura Penataran. Perencanaan penataan ini dengan pendekatan pemberdayaan masyarakat dan Kearifan Lokal, yaitu pendekatan yang menekankan pemberdayaan masyarakat dan kearifan lokal desa setempat.

Perencanaan ini harus memenuhi beberapa kaedah seperti memenuhi kaedah teknis, ekonomis, ergonomis, sesuai dengan sosial budaya setempat, hemat energy, tidak merusak lingkungan dan sesuai dengan kondisi kekinian, serta berbasis pada Kearifan Lokal (Rumawan, 2007; Sutarja, 2014 dan Taryadi, 2012). Kegiatan pengabdian ini diharapkan dapat mewujudkan hasil perencanaan penataan lingkungan pura yang mencerminkan arsitektural setempat, serta sesuai dengan keinginan masyarakat pengguna yaitu seluruh penyungsung Pura Penataran ataupun Pura Muncaksari.

\section{METODE PELAKSANAAN}

\subsection{Metode Pelaksanaan}

Perencanaan ini akan dianalisis menggunakan pendekatan Ergonomi yang difokuskan pada pendekatan SHIP (Manuaba A., 2006), yaitu: pendekatan yang Sistemik, Holistik, Interdesipliner, dan Partisipatori. Proses perencanaan akan menerapkan Teknologi Tepat Guna (Nala, 1987) dan Kearifan Lokal (Rumawan, 2007; Sutarja, 2014 dan Taryadi, 2012), sehingga akan terwujud hasil perencanaan penataan lingkungan pura yang mencerminkan arsitektural lokal, serta sesuai dengan keinginan masyarakat pengguna yaitu seluruh penyungsung Pura Penataran di areal Pura Muncaksari, Desa Sangketan, Kecamatan Penebel Kabupaten Tabanan.

\subsection{Evaluasi Pelaksanaan}

Evaluasi akan dilaksanakan bertahap dan setiap tahapan pelaksanaan perencanaan sesuai dengan jadual yang disepakati, sehingga luaran akan dapat diselesaikan secara bertahap dan berkelanjutan. Tolok ukur keberhasilan adalah setiap item kegiatan dapat diterima oleh masyarakat pengguna melalui proses musyawarah di pura. Musyawarah ini dalam bentuk FGD.

\section{HASIL DAN PEMBAHASAN}

\subsection{Hasil}

\subsubsection{Gambaran umum}

Pengabdian dipusatkan di Pura Alas Madya yang bagian dari lingkungan Penataran Pura Luhur Muncaksari, atau lebih tepatnnya berada di sebelah utara Utama Mandala. Pura Alas Madya ini 
terdiri dari beberapa bangunan, yaitu pelinggih Padma, Bale Piyasan, dan Bale Pesimpenan. Sesuai dengan namanya Pura Alas Madya ini menyatu dengan Hutan (Alas) tanpa tembok penyengker. Disekeliling pura adalah hutan dengan topografi terjal. Untuk gambaran umum tetang lokasi pura sebagai dasar perencanaan, maka diperlukan pengukuran topografi.

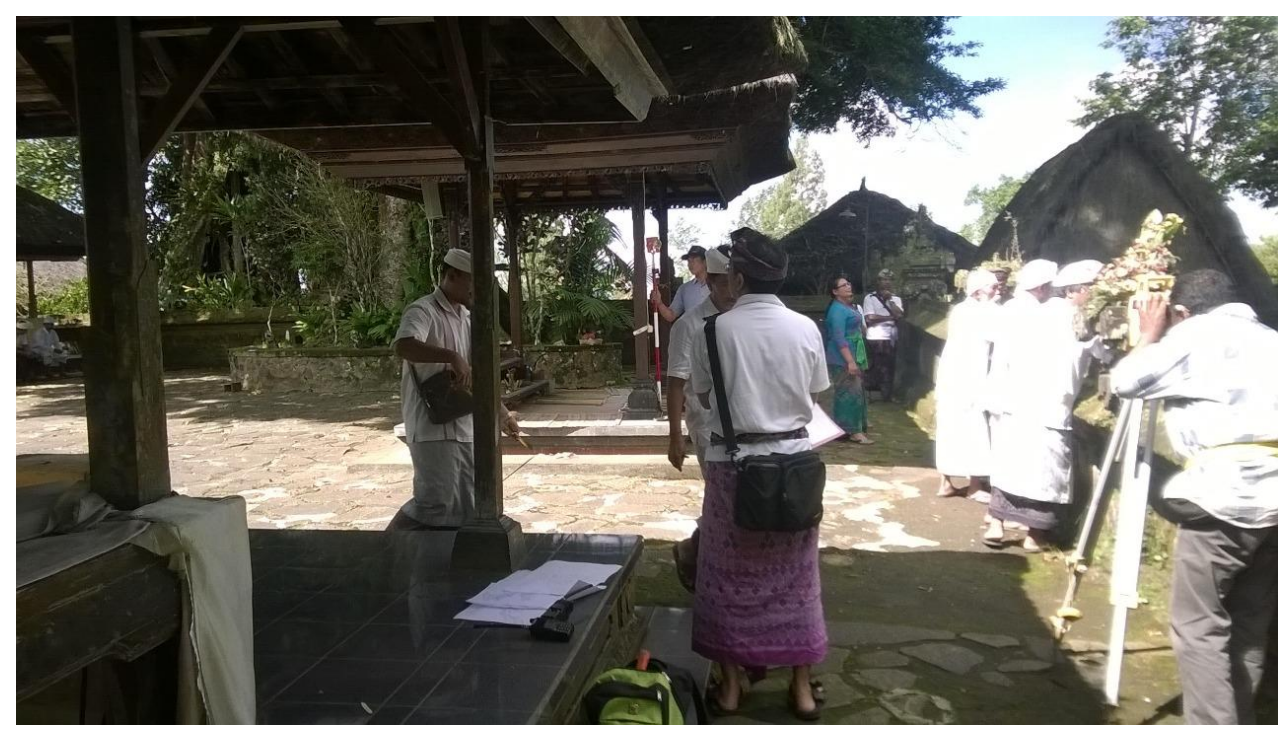

Gambar 3.1. Pengukuran Topografi di Lingkungan Pura Muncaksari

\subsubsection{Gambar Perencanaan}

Pura Alas Madya di lingkungan pura Muncaksari ini terdiri dari beberapa bangunan, yaitu pelinggih Padma, Bale Piyasan, dan Bale Pesimpenan. Sesuai dengan namanya Pura Alas Madya ini menyatu dengan Hutan (Alas) tanpa tembok penyengker. Disekeliling pura adalah hutan dengan topografi terjal. Untuk menjaga kesucian pura, dan menahan agar tanah tidak longsor maka direncanakan pondasi batu kali untuk menahan longsoran dan juga berfungsi sebagai pondasi. Dalam penataan ini juga direncanakan tembok penyengker dan candi bentar yang rendah untuk menjaga kesucian pura dari gangguan luar, namun masih menyatu dengan hutan disekelilingnya. Bahan utama dari bangunan-bangunan tersebut adalah kayu dan batu tabas. Gambar detail bangunan pelinggih, penyengker dan candi bentar terlampir. 


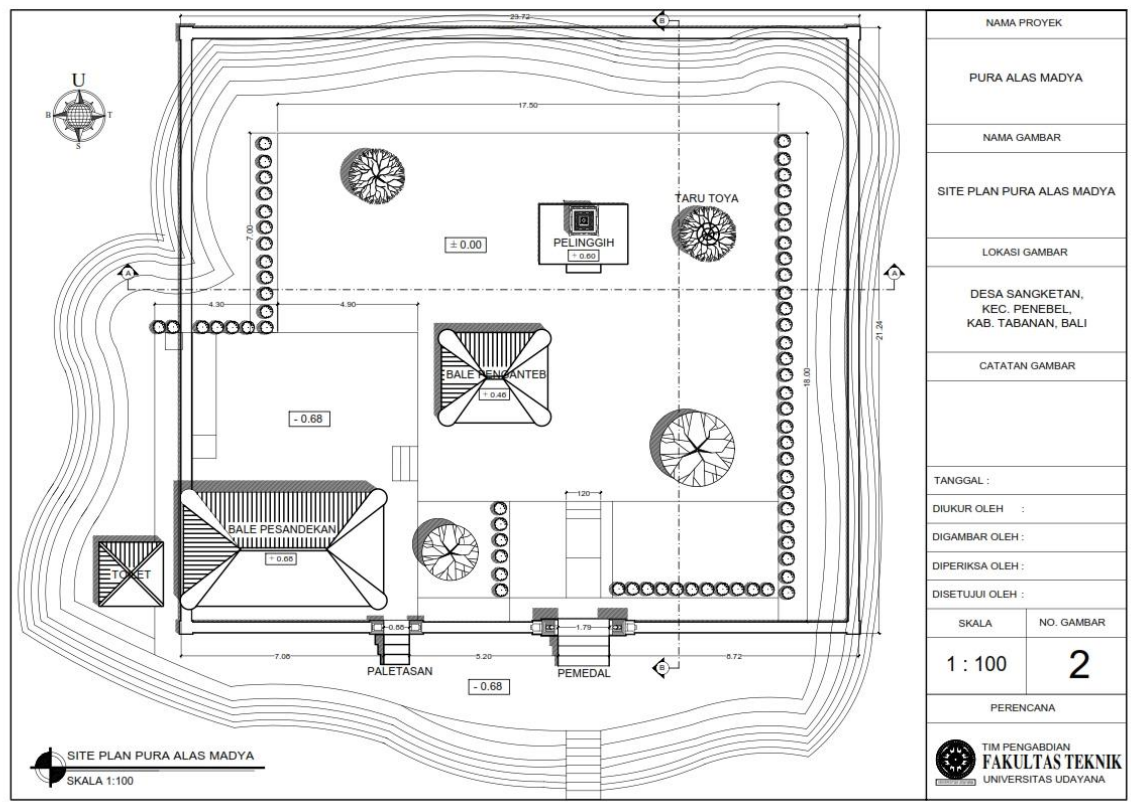

Gambar 3.2, Gambar Rencana Situasi Pura Alas Madya

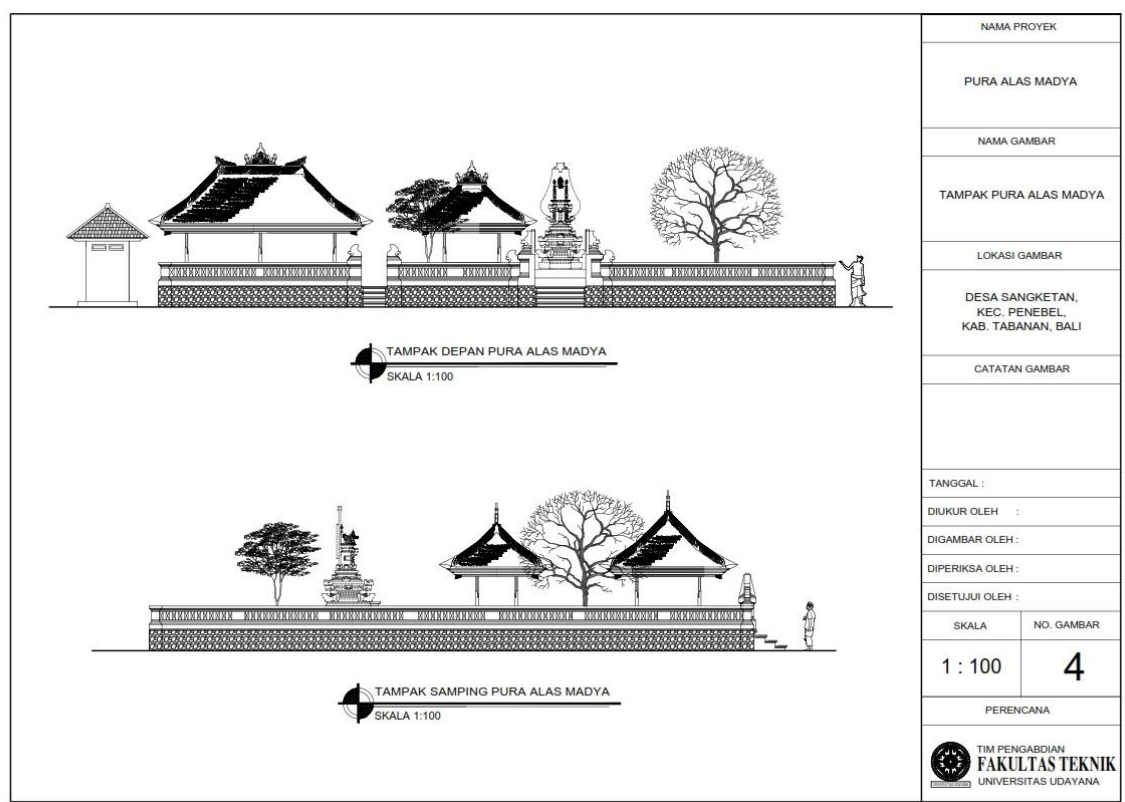

Gambar 3.3, Diskusi Gambar Rencana dengan Panitia Pembangunan 


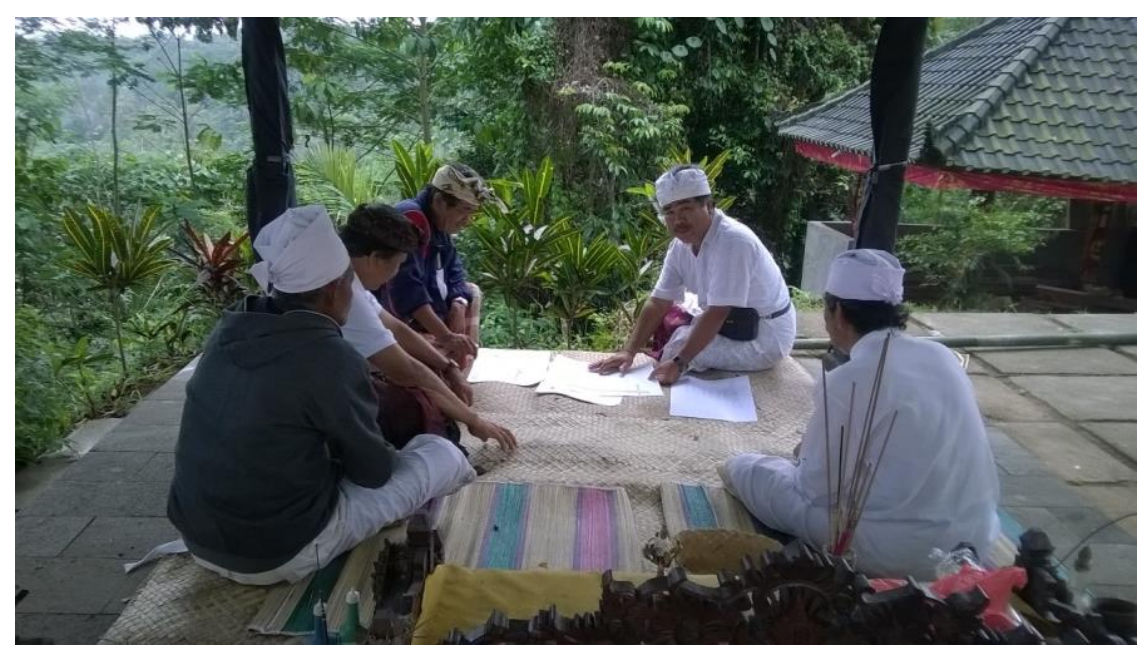

Gambar 3.4, Diskusi (FGD) Gambar Rencana dengan Pemangku

\subsection{Pembahasan}

Dalam proses perencanaan dan perancangan pura digunakan dua buah pendekatan yaitu Ergonomi yang berfokus pada Teknologi Tepat Guna (TTG) dan Kearifan Lokal, yang berfokus pada tri hita karana. Konsep teknologi tepat guna diaplikasikan dalam pemilihan bahan bangunan. Bahan yang digunakan selain ramah lingkungan, sustainable dan dapat diaplikasikan secara mudah oleh krama pengempon maupun tenaga kerja lokal, baik dalam proses pengerjaan maupun pemeliharaannya. Hal tersebut dapat menjaga kelestarian lingkungan maupun mewujudkan partisipasi masyarakat yang telah diawali dari proses perencanaan, pembangunan, pengawasan dan pemeliharaannya. Partisipasi dilaksanakan melalui paruman untuk berkoordinasi dengan pengempon, serta demikaian halnya dengan proses selanjunya.

Konsep tri hita karana dikaji dan dijadikan konsep dalam menyusun tata letak, tata bentuk dan bahan. Tata letak yang memperhatikan hirarki dan tata nilai ruang secara horisontal sehingga menyesuikan dengan mandala pura. Tata bentuk yang tersusun atas pepalihan tang terdiri atas kepala - badan - kaki sebagai implementasi dari simbul tiga lapis alam yaitu alam bhur loka/bawah- alam swah loka/tengah - alam swah loka/atas, sebagai simbul alam butha, manusia dan dewa. Bentuk ini sekalian diimplementasikan dengan pemilihan bahan : yaitu bahan dasar dengan bagian tepas dan bataran yang terbuat dari batu-batuan, sedangkan sarinya terbuat dari kayu. Konsep ini memiliki simbolis bahwa batuan melambangkan dan bermakna baat, berat atau sungguh-sungguh, sedangkan kayu bermakana kayun atau pikiran. Sehingga secara keseluruhan bangunan yang dibuat bermakna sebagai suatu keinginan dan niat yang sungguh-sungguh dan tulus untuk mewujudkannya. Dengan demikian akan terjadi keselarasan hubungan antara dewa/Tuhan Manusia - butha/unsur/alam.

Selain daripada itu, konsep tri hita karana juga diimplementasikan dalam proses kegiatan, sejak pra-rencana, lalu tahap perencanaan, dan kemudian pelaksanaan. Dalam setiap tahapan proses tersebut, konsep tri hita karana tidak lepas dari keseharian semua pihak. Tri Hita Karana dalam pengertian yang paling hakiki adalah hubungan yang harmonis antara manusia dengan Tuhan (parahyangan), hubungan yang harmonis antara manusia dengan sesame manusia (pawongan), dan hubungan yang harmonis antara manusia dengan lingkungannya (palemahan).

Sejak awal, ketika masyarakat mulai menyatukan tekad untuk melakukan perbaikan bangunan atau membuat fasilitas baru, mereka memulai dengan aspek tri hita karana yang pertama, yaitu selalu mapiuning (hatur piuning) kehadapan Ida Sang Hyang Widhi Wasa/Tuhan Yang Maha Esa, memohon agar segala kegiatan yang akan dilakukan mendapat tuntunan dan keselamatan 
- Tabanan

dariNYA.Bahkan setiap rapat/pertemuan yang dilakukan, aspek parahyangan (hubungan yang harmonis dengan Tuhan) selalu menjadi bagian awal, setidaknya dengan menghaturkan canang sari atau doa penganjali pangastuti. Ini menunjukkan bahwa masyarakat sudah sangat larut dalam penerapan aspek parahyangan.

Demikian pula dalam aspek pawongan (hubungan yang harmonis antara sesame manusia). Hubungan yang harmonis dapat terwujud jika dalam setiap langkah, ada kebersamaan , baik dalam memikul beban kerja termasuk pengambilan keputusan-keputusan. Semua pemikiran dan masukanmasukan pendapat kearah proses pembangunan, diupayakan diakomodir untuk mencapai musyawarah mufakat. Kegiatan tidak akan mencapai hasil optimal, jika diantara sesame amggota masyarakat tidak terwujud hubungan yang harmonis.

Lebih jauh lagi hubungan yang harmonis antara sesama manusia ini tidak hanya dalam lingkup sesame anggota (pengempon), melainkan hubungan yang harmonis dengan aparat desa dan aparat pemerintah (guru wisesa). Perencanaan teknis ini, yang kemudian akan menjadi dokumen pelaksanaan pembangunan ini, paling tidak akan disampaikan pada lingkungan banjar, desa/kelurahan dan seterusnya. Selain untuk mendapat restu, tentunya juga agar kegiatan poembangunan nantinya tidak mengalami sesuatu yang tidak sesuai dengan peraturan pemerintah.

Aspek terakhir adalah palemahan. Dalam hal ini, aspek palemahan adalah keharmonisan antara bangunan yang akan dibuat dengan lingkungannya. Dengan keberadaan tapak/lahan pura sedemikian rupa (laut, bakau, jalan raya, permukiman dan sebagainya), sudah tentu pertimbanganpertimbangn lingkungan perlu mendapat perhatian secara menyeluruh. Dengan jalan raya, keberadaan bangunan dan fasilitas pendukungnya, termasuk kegiatannya, tidak boleh menimbulkan kerawanan lalu lintas. Jadi proses keluar/masuk pura harus memenuhi aspek lalulintas yang aman, tertib dan lancar.

Sejak proses pembangunan, tidak boleh ada material bangunan dan sisa-sisanya, menjadi beban yang merusak atau mengganggu lingkungan. Sebaliknya, lingkunag pura harus dibuat menjadi lebih asri, misalnya dengan pemilihan jenis tanaman yang karakternya cocok di daerah ini.

Demgam model kegiatan seperti tersebut di atas, masyarakat (pengempon pura) atau siapa saja yang ikut di dalamnya, dapat melakukan pekerjaan dengan teknologi yang sesuai dengan kemampuannya. Dengan bimbingan teknis dari pihak pembimbing, pekerjaan dapat berjalan tanpa hambatan teknis yang berarti. Hal ini merupakan penerapan teknologi yang tepat guna.

\section{SIMPULAN}

Perencanaan teknis penataan sebagian dari bangunan Pura Alas Madya di lingkungan Pura Penataran Muncaksari, Penebel merupakan inisiatif dari warga, dan sesuai dengan kesepakatan mereka, dipandang perlu untuk mendapat tenaga teknis dari Universitas Udayana. Agar pelaksanaan pembangunan berjalan sesuai dengan harapan, masyarakat perlu memiliki rencana yang jelas dengan didukung dokumen (gambar, RAB, dan sebagainya) dan asistensi/pendampingan daalam setiap tahapan pelaksanaaannya.

Tenaga teknis dalam pengabdian ini telah mempertimbangkan berbagai hal agar pilihan-pilihan dalam pembangunan di kemudian hari memenuhi aspek ergonomi total (pendekatan SHIP dan Teknologi Tepat Guna) beserta berorientasi pada kearifan lokal (khususnya tri hita karana). Hal ini akan memberikan yang lebih besar untuk masyarakat berperanserta, dan pada akhirnya mereka akan memiliki kepuasan tersendiri dalam ngaturang ayah. Model kegiatan seperti itu akan muncul rasa memiliki yang lebih kuat.

\section{UCAPAN TERIMAKASIH}


Puji dan syukur saya panjatkan kehadapan Ida Syanghyang Widhi Wasa, atas segala rahmatNya sehingga penulisan paper ini dapat diselesaikan. Ucapan terimakasih pula saya sampaikan kepada pihak-pihak yang mendukung dan memberikan masukan dalam penulisan makalah ini.

\section{DAFTAR PUSTAKA}

Manuaba. A., 2006, Aplikasi Ergonomi dengan Pendekatan Holistik perlu, demi hasil yang lebih Lestari dan mampu bersaing, Jurnal Sosial dan Humaniora, Volume 01 Nomor 03:235-249.

Nala, I.G.N., 1987, Penerapan Teknologi Tepat Guna di Pedesaan, Denpasar, Lembaga pengabdian Kepada masyarakat, Universitas Udayana.

Rumawan P. S., 2007, Peran Kearifan Lokal dalam Penataan Ruang di Bali, Kearifan Lokal dalam Pengelolaan Lingkungan Hidup, Denpasar, UPT. Penerbit Universitas Udayana.

Sutarja, I.N., 2014, Pembangunan Infrastruktur Perdesaan Berbasis Ergonomi Total Yang Inklusif Dan Berkelanjutan, Udayana University Press, Denpasar.

Taryadi, S., 2012, Tri Hita Karana, Landasan Pembangunan Ala Bali, http:/green.kompasiana.com 